\title{
Transferring Ghana's system of evidence-based health program development: Program for an initial exchange with Sierra Leone and Burkina Faso
}

Frontiers in Reproductive Health

Follow this and additional works at: https://knowledgecommons.popcouncil.org/departments_sbsr-rh

Part of the Demography, Population, and Ecology Commons, Health Services Research Commons, and the International Public Health Commons

How does access to this work benefit you? Let us know!

\section{Recommended Citation}

Transferring Ghana's system of evidence-based health program development: Program for an initial exchange with Sierra Leone and Burkina Faso, FRONTIERS Final Report. Washington, DC: Population Council, 2005. 


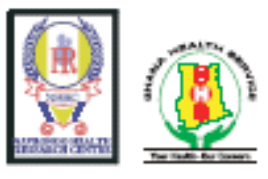

1 Population Council

\title{
Transferring Ghana's System of Evidence-based Health Program Development: Program for an Initial Exchange with Sierra Leone and Burkina Faso
}

\author{
A Report of a Meeting Hosted by the Ghana Health Service, \\ the Navrongo Health Research Centre, \\ and the Population Council \\ Navrongo, Ghana, May 12-17, 2005
}

This study was funded by the US AGENCY FOR INTERNATIONAL DEVELOPMENT (USAID) under the terms of the Frontiers in Reproductive Health Cooperative Agreement Number HRN-A-00-98-00012-00, and Population Council subaward AI05.18A and in-house subproject 5800 53092. The opinions expressed herein are those of the authors and do not necessarily reflect the views of USAID. 


\section{Acknowledgements}

The partners gratefully acknowledge the financial support provided by USAID, through the Population Council's Frontiers in Reproductive Health Program (Cooperative Agreement No. HRN-A-00-98-00012), for launching The ExCHANGE. Technical assistance was provided by Population Council staff working on another USAID-funded initiative, the Experimental Family Planning Programs in Rural Africa Settings Project, under the auspices of the Population Council Program 3 (PCP3) Cooperative Agreement HRN-A-00-99-00010.

The partners also wish to acknowledge Dr. John Williams, Mr. Robert Alirigia, and Ms. Paulina Tindana of the Navrongo Health Research Centre for all their efforts to coordinate and serve as host of the first exchange. Dr. Frank Nyonator of the Ghana Health Service provided critical guidance to the exchange as well as serving as the GHS's official sponsor and spokesman. Dr. James Phillips and his team at the Population Council in New York City provided technical assistance for developing meeting content and providing important background context, and served as facilitators and logistic coordinators for international aspects of the meeting. In particular, Ms. Ellie Feinglass is gratefully acknowledged for her championship of Sierra Leone Ministry of Health and Sanitation involvement and liaison work with the Burkina Faso team, and Mr. Barry Ravitch for serving as meeting rapporteur and preparing this meeting report. Ms. Angela Gadzekpo of the Population Council in Accra provided invaluable support to incountry logistics.

It is our hope that this will be the beginning of a successful initiative to promote the use of evidencedbased best practices in improving community-focused primary health care and family planning services in a variety of settings throughout sub-Saharan Africa. 


\section{EXECUTIVE SUMMARY}

An experimental study conducted from 1994-2004 by the Navrongo Health Research Centre (NHRC), with technical assistance from the Population Council, tested ways of deploying community health nurses to village locations and mobilizing community support, leadership, and resources for health action. The Navrongo experiment demonstrated that mobilizing community volunteerism, in combination with retraining and redeploying nurses to village-based locations reduced childhood mortality rates by 50 percent and fertility by 15 percent, equivalent to a decline of one birth in the total fertility rate. This compelling evidence led the Ghana Health Service (GHS) to implement a national program for transferring the Navrongo service model to other districts, while researching constraints to the transfer process and communicating lessons learned to health administrators across the country. Known as Community-based Health Planning and Services (CHPS), this initiative is now the Government's primary strategy for realizing universal access to health care.

With CHPS now being implemented as national policy, the GHS, the NHRC, and the Population Council began turning their attention to ways of transferring and adapting these evidence-based strategies to other countries in the region. From May 12-17, 2005, the three institutions invited representatives from the Sierra Leone Ministry of Health and Sanitation (MOHS) and the Burkina Faso Ministry of Health (MOH) to participate in the first such exchange at the Navrongo Centre. Donors and multilateral organizations that have been active in the areas of health care and family planning service delivery were also invited to attend. Funding for this exchange was provided by the Population Council through its USAID-funded Frontiers in Reproductive Health Program.

\section{The Exchange achieved four major objectives:}

\section{The exchange developed a common understanding of the Navrongo experiment and its relevance to health policy development in the region.}

NHRC researchers presented details on the background, design, implementation and the results of the experiment. Medical Directors from two pioneering CHPS districts described how the experiment was replicated and the strategy proved sound for expansion. Officials from the Ghana Health Service explained how the Navrongo model was adopted as national policy and implemented nationwide. Particular attention was paid to the use of evidence gathered at each stage of the process, and how that evidence guided the evolution of CHPS as Ghana's strategy for community-based primary health care and family planning service delivery. CHPS concepts resonated with the GHS's Burkinabe and Sierra Leonean counterparts, and discussions revealed there were indeed many areas where both health philosophies and applications are similar in other West Africa regional settings. Indeed, the two visiting teams were able to provide helpful suggestions to the GHS based on their own experiences.

\section{The Exchange provided a forum through which visiting country teams articulated their community-based health care needs.}

The Burkina Faso Ministry of Health $(\mathrm{MOH})$ is already working closely with its counterparts in Ghana to adapt lessons learned from the CHPS experience to the context of Burkina Faso. However, there had been a need for further dialogue to clarify operational details of a sustainable collaborative program involving CHPS in addressing the MOH's technical assistance needs.

In 1995, Burkina took on the challenge of developing an evidenced-based strategy to improve its community-based health services when the Bazega Experiment was launched. Among the approaches tested were the use of community-based delivery (CBD) agents to provide family planning services, and mobilized communities for preventing HIV/AIDS and eradicating female genital cutting (FGC). A 1998 
evaluation of Bazega showed the approach had potential. Burkina has since adopted a national health policy and a 10-year plan of health development that place a great emphasis on this community-focused approach, especially in rural areas. Yet there are a number of difficulties associated with Burkina's current strategy:

- Multiplicity of health care officials

- Lack of uniform training content

- A gap between concepts and the social realities of community health

- Weak motivation of community health officials

- Insufficient supervision

- Weak quality of services provided

- Weak support for the community system at other levels of the system

The $\mathrm{MOH}$, with the direction of its Family Health Division, hopes to design a strategic plan for community health that addresses each of the difficulties described above. It is hoped that the Navrongo experience will be useful in guiding this process.

The Sierra Leone Ministry of Health and Sanitation (MOHS) had had very little exposure to the Navrongo model prior to the Exchange.

Sierra Leone's health profile reveals a country suffering from numerous problems. It has high rates of infant and maternal mortality coupled with a high burden of disease. Increasing rates of HIV/AIDS infection are exacerbating the situation. Sierra Leone has a small health budget that is inadequate to meet its needs, and while 60 percent of the services currently being offered are free to vulnerable groups, health facilities are ill-equipped to meet the challenges they face. The effects of the war on the health infrastructure cannot be understated: Two-thirds of health facilities are non-functional. Staff attrition is high as a consequence of the conflict. Many health workers either retired or abandoned their posts, and others migrated to safer areas.

Sierra Leone's health system is heavily influenced by donor priorities. UNICEF and the European Union are spearheading efforts to reconstitute it and make it self-sustainable. Working in conjunction with the MOHS, a new healthcare structure is being put into place. The goals of the program and aspects of its design closely parallel those of Ghana's CHPS initiative. In addition, the partners in Sierra Leone have embarked on a pilot study in three districts. The pilot tests "mother and child survival" interventions at three levels of the system-clinic, household, and community. The main objective is to find effective ways to reduce high infant and maternal mortality rates.

Through the course of the Exchange, MOHS participants were able to identify ways in which CHPS processes could be adapted to strengthen their nascent efforts. Yet it will be necessary for Sierra Leone to make adjustments:

- Community-based workers must be retrained to provide comprehensive services

- Communication systems for referrals must be incorporated

- A logistic system must be established

- Supervision and monitoring of community-based workers must be strengthened, along with health information systems

- Community mobilization must be improved

- The concept of bringing services to the client must be integrated 


\section{The Exchange allowed all participants a forum for defining and documenting a shared vision for future collaboration.}

The meeting concluded with the drafting and approval of a consensus statement, launching an international working group to be known as "The ExCHANGE" for "The Expanding Community Health Care Accessibility Network for Governmental Exchanges." The proposed working group agreed to pursue the following goals:

- To develop and share tools for identifying and developing service innovation in community-based health care

- To monitor progress in developing, testing, and scaling up comprehensive community health coverage of all communities by affordable, efficient, and effective services

- To develop effective means of sharing tools, innovation, and experience between countries

All programs are to be designed using evidence-based, problem-solving processes for improving services, specifically in the areas of primary health care and reproductive health/family planning. Members aim to achieve this goal through exchanges that share the experiences of participating countries, expanding the evidence-base for community health development beyond national borders.

\section{Develop a sustained partnership between Ghana, Burkina Faso, and Sierra Leone}

The group agreed to begin promoting the ExCHANGE program to each of their respective governments with the goal of influencing national healthcare policy. Country teams from Burkina and Sierra Leone are working to develop pilot studies that adapt the CHPS processes to local contexts. In addition, Burkina and Sierra Leone teams will be providing guidance to their Ghanaian counterparts, promoting ideas for improving CHPS implementation based on lessons learned in other settings.

A four-member steering committee was created, with a representative appointed from each ExCHANGE country and a technical assistance representative provided by the Population Council.. The consensus statement and formal meeting reports are being disseminated to the host country governments as part of efforts to engage their support. An e-mail communication list was distributed, and an internet-based working group was created. It is hosted by the WHO International Best Practices (IBP) Consortium. Plans are in the works for convening a follow-up meeting of the steering committee to review progress and determine next steps, and the possibility of convening a one-year review and assessment is being investigated.

The newly-created Exchange aims to influence health policy planning and facilitate the development and implementation of sustainable, science-based solutions to the practical problems of scaling-up innovation. By establishing partnerships with key actors at all levels of the health system, the working group will foster links between in-country researchers, policymakers, service providers, and communities.

This report provides a description of the initial exchange and the consensus developed over the course of the six-day initial exchange. The design of the Navrongo experiment, its social context, and the outcomes of each of the strategies tested are highlighted. Information on how the experiment was adapted into a nationwide healthcare service delivery program is addressed as well as the costs associated with implementation. Cross-country comparisons with Burkina Faso's and Sierra Leone's own communitybased healthcare strategies are presented as well as recommendations to revise and improve on each 
country's program design. Finally, the text of the approved consensus statement ${ }^{1}$ is presented along with a discussion of next steps agreed upon by the ExCHANGE participants.

The agenda and list of participants, as well as a detailed meeting report are included as appendices.

\footnotetext{
${ }^{1}$ In July, a second exchange was convened between the Ghana Health Service and the Ethiopia Ministry of Health. The consensus statement was revised to include Ethiopia's strategies and goals. The ExCHANGE consensus presented with this report is the final version adopted for use by all four countries.
} 


\section{INTRODUCTION}

An experimental study conducted from 1994-2004 by the Navrongo Health Research Centre (NHRC), with technical assistance from the Population Council, tested ways of deploying community health nurses to village locations and mobilizing community support, leadership, and resources for health action. ${ }^{2}$ The Navrongo experiment demonstrated that mobilizing community volunteerism, in combination with retraining and redeploying nurses to village-based locations reduced childhood mortality rates by 50 percent and fertility by 15 percent, equivalent to a decline of one birth in the total fertility rate. This compelling evidence led the Ghana Health Service (GHS) to implement a national program for transferring the Navrongo service model to other districts, while researching constraints to the transfer process and communicating lessons learned to health administrators across the country. Known as Community-based Health Planning and Services (CHPS), this initiative is now the Government's primary strategy for realizing universal access to health care.

With CHPS now being implemented as national policy, the GHS, the NHRC, and the Population Council began turning their attention to ways of transferring and adapting these evidence-based strategies to other countries in the region. The partners proposed a series of exchanges with community, government, and non-governmental leaders for this purpose. From May 12-17, 2005, the three institutions hosted representatives from the Sierra Leone Ministry of Health and Sanitation and the Burkina Faso Ministry of Health to participate in the first such exchange at the Navrongo Centre. Donors and multilateral organizations that have been active in the areas of health care and family planning service delivery were also invited to attend. Representatives from the United States Agency for International Development (USAID), both from its Washington headquarters and its West Africa Regional Program offices based in Accra; the Netherlands Embassy to Burkina Faso; the European Union's Sierra Leone Mission; and the United Nations Children's Fund's (UNICEF) Sierra Leone Mission were in attendance. Funding for this exchange was provided by the Population Council through its USAID-funded Frontiers in Reproductive Health Program (FRONTIERS). Technical assistance was provided by Population Council staff working on another USAID-funded initiative, the Experimental Family Planning Programs in Rural Africa Settings Project, under the auspices of the Population Council Program 3 (PCP3) Cooperative Agreement.

The exchange aimed to develop a common understanding of the Navrongo experiment and its relevance to health policy development in the region. It also provided a forum through which visiting country teams articulated their community-based health care needs, and allowed all participants a forum for defining and documenting a shared vision for future collaboration. Thus, the exchange became the initial step in the process of developing a sustained partnership between Ghana, Sierra Leone, and Burkina Faso.

The meeting concluded with the drafting and approval of a consensus statement, launching an international working group to be known as "The ExCHANGE" for "The Expanding Community Health Care Accessibility Network for Governmental Exchanges."

\footnotetext{
${ }^{2}$ Population Council assistance to the experiment was provided through USAID and Rockefeller Foundation funding and administered initially under the Council's Africa OR/TA II Project and subsequently under the PCP2 and PCP3 Cooperative Agreements.
} 


\section{THE NAVRONGO EXPERIMENT MODEL}

Ghana's Community-based Health Planning and Services (CHPS) processes for providing primary health care (PHC) and family planning (FP) services are based on evidence gleaned from a 10-year longitudinal experiment conducted by the Navrongo Health Research Centre (NHRC), located in the country's Upper East Region. Known as the Community Health and Family Planning (CHFP) Project, this experiment tested several different PHC and FP service delivery models for remote, underserved communities. The CHFP demonstrated that mobilizing community volunteerism, in combination with retraining and redeploying nurses to village-based locations reduced childhood mortality rates by 50 percent and fertility by 15 percent, equivalent to a decline of one birth in the total fertility rate. Independent confirmation of the CHFP's most successful strategy, undertaken and documented by the Nkwanta Health Development Centre (NHDC) in the Volta Region, provided further evidence to the Ghana Health Service (GHS) of the model's impact and sustainability. In order for participants to understand clearly why CHPS processes are implemented in the present manner, it was deemed necessary for the exchange to begin with an explanation of the background, social setting, experimental methods used, and demographic evidence gathered that provided the basis for launching the initiative.

\section{Background and Design of the Experiment - Presented by Dr. John Williams, Principal Investigator, CHFP Experiment}

Prior to the experiment's inception, evidence confirmed that Ghana's PHC and FP service delivery strategies were not effectively reaching their intended audiences, and health outcomes were poor. Fixed facilities located in major population centers throughout the country were the main points of service. Rural residents, who comprise the majority of the population, were not well served by this model. Geographic barriers to access and variations in service quality were the primary reasons for poor outcomes. Over the years, the government made efforts to increase coverage, but evidence showed that geographic barriers and quality issues remained impediments.

An assessment conducted in 1993 by the NHRC on behalf of the MOH would begin to show the way. In the early 1990s, the Population Council was developing a collaboration with the NHRC to test ways of increasing FP use in rural African settings. Together the two institutions conducted qualitative research to determine what types of services were desired and what strategies would be most effective. The results confirmed that community involvement was critical to program success. Respondents reported that the design and implementation of any new or revised system must be done in close consultation with them. Service points needed to be brought closer to the people. A doorstep delivery approach was viewed as an important aspect of this vision. Most important, respondents stressed that any FP service delivery strategy could not succeed if the community's main priority was not addressed:

\section{Let our children live.}

In short, any program designed needed to first deal with the high levels of childhood mortality pervasive within their communities. Then and only then would the people accept interventions targeted at other health-related concerns.

While it was apparent that a community-level tier needed to be added to the existing service delivery structure, a question arose: Who was the agent best suited to provide services and improve health? One theory argued that volunteers providing first aid, conducting basic triage and referrals to the health centers, and providing low-level "over-the-counter" medications and contraceptives was the best strategy. Another theory advocated using certified health workers redeployed to the communities, thus providing a broader range of PHC and FP services and referring only critical cases to the health centers and hospitals. 
Regardless of strategy, there was agreement that the services offered at existing health facilities needed to be upgraded and systems implemented to insure consistent quality.

The CHFP was borne out of this evaluation. The primary goals were to determine how best to improve access to services and to examine the demographic effect of improved health care delivery. It was set up as a four-cell factorial experiment designed to test each of the competing service delivery strategies and their respective impact on both of the CHFP's primary goals.

Figure 1 Cells in the experimental design

\begin{tabular}{|c|c|c|}
\hline \multirow[t]{2}{*}{ Mobilizing MOH outreach services: } & \multicolumn{2}{|c|}{ Mobilizing traditional community institutions: } \\
\hline & No & Yes \\
\hline No & $\begin{array}{l}\text { Control } \\
\text { Cell } 4\end{array}$ & $\begin{array}{l}\text { Volunteers only } \\
\text { Cell } 1\end{array}$ \\
\hline Yes & $\begin{array}{l}\text { MOH nurses only } \\
\text { Cell } 2\end{array}$ & $\begin{array}{c}\text { MOH nurses \& volunteers } \\
\text { Cell } 3\end{array}$ \\
\hline
\end{tabular}

In Cell 1, volunteers were deployed in the communities. In Cell 2, MOH nurses stationed at the health centers were redeployed to the community level. In Cell 3 a combination of volunteers and nurses were engaged, each assigned specific complementary tasks. In all cells with nurses and volunteers, doorstep delivery of services to women and children was an integral part the design. In Cell 4, the existing Ghana $\mathrm{MOH}$ service delivery model remained in place. In all four cells, facilities were upgraded and improved quality of care measures were put in place.

The experiment tested two additional aspects of service delivery:

- Mobilizing community-based health services. In the volunteer-only and control cells, the experiment mobilized the existing primary health care staff and program resources of the $\mathrm{MOH}$ to provide effective health and family planning care at the community level.

- Mobilizing traditional communities. In the nurse-only and combined cells, the experiment mobilized the traditional social institutions of chieftaincy, lineage, volunteer societies, among others. for planning and implementing service delivery. In addition, they collaborated on communicating family planning and reproductive health messages to both men and women. Such consultations also led to the practice of gaining consensus by the community on each volunteer recruited prior to deployment. Communities also provided supervision and support for the volunteer cadre.

These interventions were designed specifically to collect empirical evidence on the impact of the community participation and involvement so strongly advocated in the initial assessment, as well as links between the newly-established community health tier and the existing health facilities.

The experiment also placed an emphasis on male involvement. Male acceptance was critical to both access and support for program activities (as described in greater detail in the section below). Women's groups were enlisted to assist with appropriateness and context of services offered to women and children. 


\title{
The Social Context of the Experiment - Dr. Patricia Akweongo, NHRC Demographer
}

The CHFP experiment was implemented in the Kassena-Nankana District, located in the Upper East Region of northern Ghana. It is a rural, traditional society with a male-dominated power structure. Men maintain economic and social control within the communities, and a male-lineage inheritance system exists. Males serve as lineage, compound, and household heads. Even men with no leadership role have a higher social status than women.

\section{Family \& Authority Structure of the Kassena Nankana District}

\section{Lineage Head}

\section{Compound Head}

Household Head

\section{Other Male Members}

Grandmothers \& Mothers-in-Law

Young women

A similar hierarchy exists within the political structure, where male chiefs are at the top and women's groups at the very bottom.

\section{Mobilizing the Traditional Political Structure}

\author{
Paramount Chiefs
}

Divisional Chiefs

\section{Sub-divisional Chiefs}

\section{Elders}

\section{Women Groups}

Low educational levels among women limit autonomy. Early marriage is common, a situation in which age disparities further erode women's decision-making power. Women often have to seek permission to access health care for themselves and their children. Of equal importance to the experiment, men have the final say on reproduction. Compounding the problem were challenges associated with a male preference for high fertility. A major challenge, therefore, was to overcome men's fears of FP and women's anxieties regarding the consequences of discussing the subject. The services offered through the CHFP were provided primarily to women and children through doorstep delivery. This placed the 
strategy at odds with the social and political structure of the community, as it designates the lowest tier of the system as the point of entry. It was therefore critical that traditional political structures be actively engaged in order to overcome household and family norm biases.

\section{CHFP Implementation Part I: The Pilot and Scale-up -Ms. Rofina Asuru, Medical Director, Kassena-Nankana District}

The first major task confronted by program implementers was identifying an appropriate package of goods and services for community health nurse care. Then a system to train those delivering services needed to be developed, along with a facilitative supervision system. A monitoring and evaluation (M\&E) system had to be incorporated. There was a need to improve the health centers. The program also had to account for issues of morale among the cadre of nurses who were going to be redeployed. The CHFP team was concerned that the nurses would feel neglected and isolated if they were moved a great distance away from the health center.

Heeding the lessons learned regarding involvement of the people, the NHRC and its partners reached out to all levels of the system when designing the CHFP approach. They also held in-depth discussions with the traditional power structures. Meetings were held with the Kassena-Nankana District (KND) Chief Executive and the Districts Assembly. These led to the securing of political commitment for the project, marshaling of financial/material support for community-initiated projects, and promoting general interest in project activities.

Once support was obtained, the CHFP completed the pilot design and began the processes of implementation. The package of PHC and FP services decided upon for the pilot were as follows:

- Preventive and Promotive: Conducting health education talks and providing informational materials and immunization services

- Reproductive Health: Providing antenatal care, performing uncomplicated deliveries, providing post-natal care, CWC, and FP counseling and service delivery.

- Curative: Providing treatment for malaria, ARI, diarrhea, skin diseases, and first aid for minor injuries

- Referrals: Arranging appropriate referrals for advanced medical conditions, and provision of FP methods such as IUD and Norplant ${ }^{\circledR}$.

- Community mobilization for health action: Holding community meeting (known as durbars) and generating discussion about important health issues, leading to decision-making among local residents

Then the team turned its attention to the elements necessary for deploying the nurses, volunteers, and supervisors:

- Community health compounds (CHC). Nurses redeployed to communities required living quarters and space to provide services beyond that provided at the doorstep. The solution was to construct or renovate buildings that would serve both these objectives. Leaders and individual community members were mobilized to assist with construction and/or renovation.

- Training. A four-week training was conducted for Community Health Officers (CHO), the title given to nurses recruited for the program. Training consisted of two weeks of theory and two weeks of practical application. Supervisors at the district and subdistrict levels also received an orientation to the CHFP model.

- Volunteers were recruited, two per community, and provided with training on the treatment of minor illnesses, on how to conduct environmental sanitation talks and on providing FP 
counseling and referrals. Five-member health committees were established in each community. to serve as supervisors for the volunteers.

- Essential equipment. CHOs were provided with motorbikes and volunteers with bicycles. Drugs; contraceptives; and information, education and communication (IE\&C) materials were purchased either directly by the project or through existing regional and district medical services.

- M\&E. A health management information system was created, comprised of household registers and cluster reports designed to capture demographic information and health status, monthly activity report forms, and referral forms.

Once all these elements were in place, durbars were held to introduce the CHOs and volunteers to their respective community.

Throughout the pilot, supervisors conducted routine monitoring visits to the $\mathrm{CHO}$. Refresher trainings were conducted periodically, specifically tailored to address issues revealed in supervisory reviews and to provide instruction on new and updated $\mathrm{MOH}$ policies.

The results of the pilot were promising, both in terms of improvement of health outcomes and reaction to the service delivery strategy. Between 1995 and 1996, the experiment was scaled up district-wide. A total of 16 communities were engaged. Four separate experimental areas were established to test multiple intervention strategies (as described in the background section).

The intervention design remained essentially intact from that used in the pilot, with the following changes based on lessons learned:

- All CHO were housed in separate dwellings.

- The project facilitated communities' negotiation for support from individuals and District Assemblies for supplies and essential equipment.

- $\mathrm{CHO}$ spouses were more actively engaged in CHO activities. CHOs were given weekends off to be with their families, and spouses were invited to participate in social interaction sessions

- An additional two weeks was added to the $\mathrm{CHO}$ training to provide for a comprehensive background in midwifery skills

- Durbars primarily focused on the FP concerns of men were conducted

- A team of eminent persons within each community was constituted to resolve disputes between the $\mathrm{CHO}$ and community members

\section{Implementation Part II: The Specific Role of the Community Health Officer (CHO) - Mr. Robert Alirigia, Field Coordinator, NHRC}

The CHO serves as the leader and facilitator of the community health team. She is the liaison between the community and district and subdistrict levels of the health system. She is a "prime mover," ensuring community members wellbeing by promoting and maintaining good health, providing adequate treatment of the sick and promoting good health practices. She serves as part of the supervisory team for program volunteers and oversees the work of traditional birth attendants within her community. She ensures community collaboration on activities, provides information on health problems, including sanitation campaigns, immunization campaigns, and health education talks at durbars. 
The CHO's duties include, but are not limited to:

- Provision of health services via doorstep delivery. The $\mathrm{CHO}$ conducts home visits on a regular basis, visiting each compound once within a 90-day cycle. During these visits, the CHO examines immunization records for all children under 2 years of age, provides ante- and postnatal care, manages routine deliveries and treating obstetric complications, referring cases to health facilities when necessary.

- FP service-delivery agent, both at the doorstep and at the CHC. The CHO counsels clients on all FP methods, provides the chosen method, and maintains an adequate re-supply for users. $\mathrm{S} /$ he conducts follow-up visits for continuing users and tracks down clients lost to followup/discontinuers. As part of post-natal follow-up, the CHO provides FP counseling and services.

- Primary health care provider for the community. In this capacity, the CHO is responsible for treating common ailments and responding to health-related emergencies. S/he identifies communicable and non-communicable diseases in homes and the community and provides curative services.

- Disease control surveillance at the community level. The $\mathrm{CHO}$ performs disease surveillance and control according to national guidelines, applying appropriate procedures for reporting unusual occurrences to the district and subdistrict levels.

- Serves as the frontline of the Expanded Program on Immunizations (EPI) in Ghana. The $\mathrm{CHO}$ educates individuals and families on vaccine-preventable diseases, conducts routine immunizations, with particular attention to infants and children, and maintain the cold chain according to national standards. S/he also is the local agent for nationwide immunization campaigns, overseeing the roll-out and proper reporting of coverage to the appropriate levels.

- Serves the health care needs of the school system. CHOs collaborate with the Sub-district health team to carry out school health activities, participating in the design of school healthcare programs. S/he also provides health education talks, and assists the schools themselves in maintaining good health and sanitation practices.

Overall, the CHO within the CHFP/CHPS model is seen as a "change agent" and not just a "task performer." The roles appear daunting at first. However, comprehensive training and refresher training programs allow the $\mathrm{CHO}$ to have such a broad mandate. Indeed, as mortality has declined within the CHFP area, preventive care and FP have become greater priorities.

The CHPS initiative has adapted the CHFP model to deploy two CHOs per zone to address issues of coverage and scope of work. CHOs are also trained to know what to refer and when in order to avoid overburdening themselves.

\section{The Impact of the Experiment - Dr. Ayaga Bawah, Director, Demographic Surveillance System, NHRC}

In order to assess the experiment properly, several different methods of evaluation were developed. The main source of data is from the Navrongo Demographic Surveillance System (NDSS), which monitors all demographic events prospectively - births, deaths, migrations, marriages, and pregnancies - that occur in the lives of all individuals residing in the Kassena-Nankana District. The system also provides continuous estimates of fertility rates for approximately 43,000 women of reproductive age.

The data presented here show trends in demographic indices over the life of the CHFP and the association between these changes and the intervention. 
Results indicate that fertility within the study district has declined rapidly over the last decade, from 5 births per woman down to 3.9. While fertility has declined throughout the district, it is greater in areas where a health professional is present

Mortality rates remain high in the Kassena-Nankana district, although it must be noted that they have also declined considerably over the last decade. Yet again, significant gains in childhood mortality reduction over time were achieved when comparing the intervention cells with the control. The largest gains in reduction of childhood mortality occurred in the nurse-only cell.

Contraceptive use has also risen throughout the district, and that increase is most dramatic and has been best sustained in the combined cell:

Current use of modern contraceptive methods among married women aged 15-49 by CHFP cell

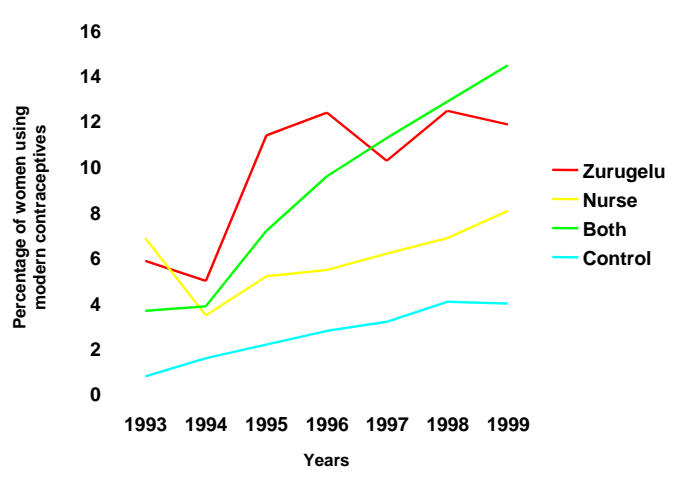

A number of regressions were run adjusting for other likely causes of the effects observed. In Cell 3 (the combined nurse-volunteer intervention), educational attainment had a large effect on FP and fertility outcomes, more positively associated than anticipated. Regardless, when controlling for education, the level of effect attributable to the experiment is great enough to be able to declare program success.

Based on this analysis, it was determined that the nurse-deployment strategy has the greatest effect on reducing childhood mortality. However, the combined nurse-volunteer cell not only has a significant effect on mortality, but it also has the greatest effect on reducing fertility and increasing contraceptive use. It is this combination of positive outcomes that led the CHFP team to determine that the nursevolunteer deployment strategy was the most effective method of service delivery.

\section{REPLICATION OF THE CHFP}

\section{The Nkwanta Story - Dr. J. Koku Awoonor-Williams, Medical Director, Nkwanta District; Director, Nkwanta Health Development Centre; National CHPS Coordinator, Ghana Health Service PPME Division}

By 1997, evidence indicated that the CHFP intervention strategy in the combined nurse/volunteer cell was having a profound impact. However, stakeholders were concerned that the CHFP could not be replicated without the inputs from a full-service research institution and considerable donor support. It would be necessary for someone to demonstrate replication without such inputs to provide the impetus for scaling up the experiment. Enter the Nkwanta District Health Management Team (DHMT). 
The Nkwanta District, located in the Volta Region of eastern Ghana, is another remote area of Ghana facing similar challenges to those encountered within the Kassena-Nankana District. Local officials were eager to improve healthcare access to the most marginalized communities. The Nkwanta DHMT recognized the need for an innovative approach. The Nkwanta team had had the opportunity to observe the Navrongo experiment first hand, and believed this strategy was the approach they were seeking. They decided to take on the challenge of replicating the CHFP, working in consultation with the NHRC but without the high-level inputs available to them. The Nkwanta experiment sought to answer the following questions:

- Is the CHFP design feasible?

- Can a volunteer system work?

- Will the CHOs be accepted and integrated into the communities?

- What is the optimal training package?

- What is a viable work routine for this initiative?

- Can the DHMT provide adequate monitoring and support?

- Can a community-based information system be developed that is effective?

Two pilot communities were selected for initial implementation. As was the case in the Navrongo experiment, all health, traditional, and political authorities were consulted. Community health nurses were selected and trained to become the first CHOs. The DHMT worked with the communities to ensure provision of temporary accommodations, while at the same time mobilizing them to begin construction of CHCs. Volunteer cadres and an overseeing Volunteer Health Committee (VHC) were established in conjunction with $\mathrm{CHO}$ deployment. The DHMT developed community registers to be managed/maintained by community members. A district-level supervisor was appointed to oversee the experiment, a position which became known as the CHPS Coordinator within the national program. Baseline EPI and Safe Motherhood surveys were undertaken to assess program impact.

The results of the pilot were extremely promising. No maternal deaths were reported in the catchment zones during the first two years of implementation. Both clients and providers reported significant improvements in both access and quality of care at the periphery. Service statistics clearly demonstrated a considerable increase in utilization, expanded immunization coverage, a reduction in measles incidence, and a significant reduction in cases of routine deliveries presenting at the district hospital. A more rigorous demographic impact survey conducted in 2002 by the Ghana Health Service, in collaboration with the Population Council, confirmed these results. The survey also documented evidence of an increase in FP method use over time.

The Nkwanta replication showed that:

- the Navrongo model is both feasible and highly effective

- the Navrongo model of service delivery is more culturally appropriate than alternative approaches

The pilot also revealed that while resources can indeed be mobilized internally - particularly in the form of volunteerism - external support will still be essential if the processes are to be expanded and replicated.

The Nkwanta experience provided another important guiding principle for expansion and replication:

- The Navrongo model should be understood as a process of developing community-based services according to local needs and circumstances, rather than simply as a process of 
replication. In this sense, each DHMT must regard scaling-up as a significant step towards decentralization and community empowerment.

\section{THE COMMUNITY-BASED HEALTH PLANNING AND SERVICES (CHPS) INITIATIVE}

\section{Introduction - Dr. John K. Awoonor-Williams}

Nkwanta demonstrated that the Navrongo experiment could be successfully adapted according to local needs and circumstances. Based on these results, the Government of Ghana in 1999 launched a process of transitioning to community-based health care delivery based on the Navrongo model, taking into account the adaptations developed in Nkwanta. The new nationwide health service delivery model was to become known as the Community-based Health Planning and Service Initiative - CHPS. The recently established Ghana Health Service (GHS) began working with regional and district health management teams to implement CHPS.

CHPS advocated the following guiding principles:

- $\mathrm{MOH}$ nurses are to be re-trained as $\mathrm{CHOs}$ and relocated to clinics at the community level.

- CHOs are to provide fixed-facility services and regular door-to-door visits

- A program of community supervision, accountability, and ownership of health activities is to be established.

- CHPS is to draw on already-existing community resources to support implementation.

- Community mobilization and sustained participation are essential for CHPS to succeed.

- Chiefs, elders and other leaders are to be mobilized community volunteer labor for construction of a Community Health Compound (CHC), i.e., the clinic.

- Village Health Committees and Volunteers are to be selected for each CHPS zone to provide supporting services

The official CHPS service package includes the following:

- Reproductive Health: Training and supervision of TBAs, providing antenatal care, monitoring/referral of high-risk obstetric cases, attending uncomplicated deliveries, providing postnatal care, CWC, treatment of STIs, and providing FP counseling and services

- Curative: Treatment of malaria, ARI, diarrhea, IV therapy, skin diseases, parasites, snake bites, first aid for minor injuries

- Preventive: Conducting health education campaigns, providing immunizations, promoting environmental sanitation, oral health, and nutrition

- Referrals: Providing referrals for treatment at secondary and tertiary facilities and conducting follow-up on patients upon their return

- Community Mobilization for Health Promotion: Conducting individual and communitywide educational discussions and advocacy activities 


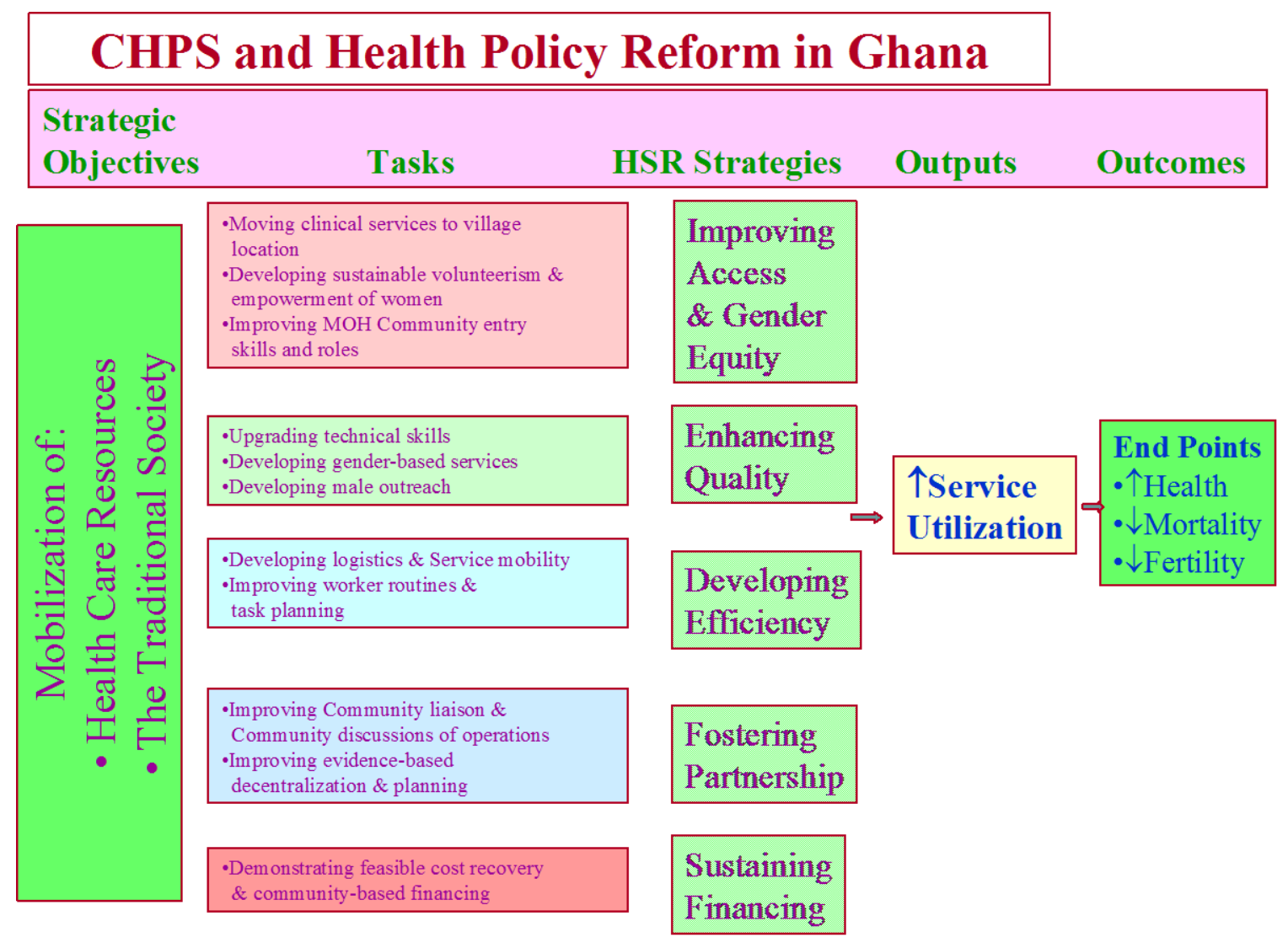

The above diagram outlines the current system for scaling up CHPS nationwide and the expected outcomes. The inputs, or tasks, are based on the CHFP model and lessons learned from Nkwanta and other innovating districts. In turn, the expected outputs/outcomes are logical expectations, as they reflect the body of evidence to date showing these to be achievable if CHPS is implemented properly.

The national level of the GHS is actively engaged in turning this model into reality. Its contributions to CHPS-scale-up are made possible through a framework developed to catalyze change in the current health system.

\section{National policy statements and guidelines}

A series of national policy statements have been issued formally declaring the Government of Ghana's commitment to CHPS as the way forward. It has been incorporated into the GHS's current five-year plan of action. A CHPS Operational Policy was developed by the MOH/GHS. It officially declares the government's overarching goal to be improving the health status of all people living in Ghana, by facilitating actions that empower persons at the household and community levels. The government envisions all Ghanaians being covered by community-based service delivery, using CHPS, by 2015 . Implementation is prioritized to those areas in most need now, that is, those areas with the least access to services and poorest health outcomes. 


\section{Strategic Plans}

The MOH/GHS has embraced a CHPS strategic plan of action for the national level. It includes developing a process for strengthening human resource capacity for rolling out CHPS, that is, establishing appropriate training facilities and CHPS-focused curriculum, recruitment and retention of qualified health workers to provide services, and the recruitment and retention of qualified persons to supervise and evaluate CHPS workers and processes. The central government is also responsible for providing and improving the infrastructure and logistics necessary to offer CHPS services. This includes insuring systems are in place to obtain the materials to build and maintain $\mathrm{CHCs}$, to purchase equipment and supplies necessary to maintain a cold chain, proper medical equipment and pharmaceuticals, motorbikes, boats, and bicycles for doorstep service delivery, communications equipment for referrals, and furnishings for CHCs.

The GHS is committed to strengthening the rest of the health system to support CHPS. This includes sensitization of medical associations and policymaking bodies to encourage their cooperation. Disease control efforts are being integrated into the CHPS delivery system as well.

\section{Monitoring and Evaluation (M\&E)}

The CHPS M\&E Secretariat, located within the GHS's PPME Division, has direct oversight of all activities to monitor and evaluate CHPS processes. The PPME has developed an official framework for M\&E:

\section{Framework for Monitoring and Evaluation of} Programme

\begin{tabular}{|c|c|c|c|}
\hline & $\begin{array}{l}\text { Dissemination } \\
\text { and Exposure }\end{array}$ & $\begin{array}{l}\text { Implementation/ } \\
\text { Operations }\end{array}$ & Output \\
\hline Process Description & $\begin{array}{l}\text { - Conferences and Consensus } \\
\text { building meetings } \\
\text { - Training - DISHOP, Counter- } \\
\text { part training, other } \\
\text { - Study Tours }\end{array}$ & $\begin{array}{l}\text {-Policy-Strategic Plan- Annual Program } \\
\text { of Work (APOW) } \\
\text {-Steps and Zones } \\
\text { - Exposing communities to CHPS }\end{array}$ & $\begin{array}{l}\text { Improved Community- } \\
\text { based Service Provision } \\
\text {-Improvement in Health } \\
\text { status indicators. (Impact) }\end{array}$ \\
\hline Indicators & $\begin{array}{l}\text {-No of Trainings Conducted } \\
\text {-No Conferences and } \\
\text { Meetings on CHPS conducted. } \\
\text { - Degree of awareness of } \\
\text { process }\end{array}$ & $\begin{array}{l}\text {-\# of districts with CHPS zones } \\
\text { - Total \# of CHO's deployed }\end{array}$ & $\begin{array}{l}\text {-Improvement in Service } \\
\text { delivery data } \\
\text { EPI, FP and others } \\
\text {-Health status } \\
\text {-Health related outcomes } \\
\text { Sanitation, School } \\
\text { Health Services }\end{array}$ \\
\hline $\begin{array}{l}\text { Mechanisms and } \\
\text { Methods of Analysis }\end{array}$ & $\begin{array}{l}\text { - Rapid Appraisals Protocols } \\
\text {-Structured Questionnaire }\end{array}$ & $\begin{array}{l}\text { - Development of Database } \\
\text {-Rapid appraisal }\end{array}$ & $\begin{array}{l}\text {-Management Information } \\
\text { Systems } \\
\text {-Survey Methods } \\
\text { Rapid Appraisal } \\
\text { Methods } \\
\text { SPA } \\
\text { FGD }\end{array}$ \\
\hline
\end{tabular}

Since its founding in 2001, the Secretariat has used four main M\&E tools - the M\&E database, qualitative system appraisals, demographic impact surveys at the regional and district levels, and the CHPS website to assess CHPS. 
The CHPS M\&E Secretariat collects data quarterly on the extent of CHPS implementation throughout the country. Monitoring forms are filled out and submitted by district and regional health management teams every 90 days. What has been learned from this system:

- The majority of districts (110/138) have started the CHPS implementation process

- An implementation gap exists - many districts have not moved beyond the planning stage

- Only nine districts have established one or more "completed" zones

The Secretariat conducted qualitative assessments with CHPS workers in four of the ten regions in order to gauge the strengths and weaknesses of the service delivery system. CHPS workers' opinions are viewed as essential for understanding challenges the system faces on the front line. Demographic impact assessments of CHPS are conducted using a tool created by Nkwanta. To date, three demonstration district surveys have been completed, and two additional have just been completed. These have shown that CHPS has a positive impact on the number of persons' receiving treatment, the number of FP users, the number of women receiving SM services, and the number of children being immunized. They also identify areas where CHPS has had no measurable impact or requires improvement to increase impact. A regional assessment was also conducted. However, because of the limited spread of CHPS region-wide, no significant impact on health outcomes can be associated with CHPS at this point in time.

The Secretariat also maintains a website - www.ghana-chps.org. The site is used as a resource to share information on CHPS history, its processes, implementation progress, and to disseminate research findings, among other things.

\section{Key Challenges}

GHS PPME has identified key challenges to nationwide upscaling of CHPS:

- The number of CHOs required for nationwide CHPS coverage is 6,624. Currently 2,370 exist and are deployed. There is also a need to identify geographical demand patterns and match them to the available supply of CHOs.

- Long-term human resource challenges include increasing the number of qualified applicants being place in pre-service training schools. The MOH/GHS is committed to establishing one training school per region.

- The GHS must work to better define the basic service delivery package. In particular, policies must be changed that prevent $\mathrm{CHOs}$ from providing services that they could otherwise realistically be providing, such as insertion and removal of IUDs.

- There is a need to shift resources dedicated to service delivery down to the district level and away from national and regional ones. Currently, district levels receive an average of 40 percent of "Total Health Recurrent" expenditure. This will be scaled up soon to 46-50 percent.

\section{Training and Manpower - Ms. Rofina Asuru}

In 1997, the MOH began to develop a system-wide approach to improve training for service providers and address staffing shortages at the district and community levels. The MOH worked closely with regional and district health management teams to design the system, the idea being that districts would gain the capacity to properly train and deploy health workers themselves. In addition, the MOH worked to establish relevant training programs and curriculum at a series of community health nurse training schools (CHNTS) and at the School of Public Health at the University of Ghana. These institutions are the venues where potential health workers obtain theoretical and practical experience in community-based health service delivery prior to assignment at the district level. 
The issues of training and manpower development took on even more importance with the introduction of CHPS as national policy. The recently established GHS saw that making improvements in these areas was also a way to generate DHMTs' interest in CHPS and produce the frontline staff necessary to scale up CHPS.

\section{Training}

CHPS incorporates two different types of training - horizontal and vertical. Horizontal training involves nurses and volunteers being trained by a tutor or teams of tutors. The purpose is to upgrade technical skills. Vertical training involves teams of managers and workers being trained by their peers. This type of training is designed to change/improve job performance through practical application, by "seeing and learning and doing." Vertical training is the technical term for the field exchange model described below. Evidence shows that when a system combines horizontal and vertical training, that system can implement change on a large scale.

The strategy used to conduct CHPS training and manpower development was based on evidence that districts where staff participated in hands-on training in Navrongo or Nkwanta were more successful with CHPS implementation. Teams of workers at all levels of the system - managerial, administrative, and operational - are trained together in designated demonstration districts. Exchange visits consist of an orientation into CHPS policies and practices. This is followed by a field practicum, during which potential workers and supervisors are paired with a counterpart already serving in the same capacity. For example, $\mathrm{CHO}$ candidates live with the $\mathrm{CHO}$ at the $\mathrm{CHC}$, providing treatment at the clinic and accompanying the $\mathrm{CHO}$ on rounds. Supervisory visits are conducted by the host DHMT, a tutor who explains processes along the way, and the visiting DHMT supervisory team. Candidate supervisors also spend a day directly observing the $\mathrm{CHO}$ go about their business. Then the participants reconvene for a series of discussions in which reactions to what was done/observed are documented and lessons learned imparted.

Teams from demonstration districts follow up training with visits to implementing districts to observe CHPS in progress. A similar field practicum is conducted, but in reverse as the trainee escorts the demonstration team around. The visiting team then provides guidance and recommendations for improvements in service delivery based on what has been observed.

Another aspect of training addressed in the MOH/GHS strategy is educating people about CHPS at all levels of the system. CHPS implementation is documented in newsletters series, which are used as training resource material and informational material for stakeholders. Information on CHPS practices and research conducted to assess CHPS implementation and practices are presented at national and regional conferences dedicated to health service delivery and health promotion.

\section{Pre-Service Training}

\section{Visit to the Navrongo Community Health Nurse Training School (CHNTS) - Ms. Rufina Asuru; Dr.} David Amalba, Principal, Navrongo CHNTS; and Navrongo CHNTS Students

In response to a staff shortage for district-wide scale up of CHPS, the Kassena-Nankana DHMT worked with district leaders and the NHRC to establish the Navrongo Community Health Nurse Training School. This CHNTS, unlike its counterparts, is operated as a day school and thus lacks residential facilities. The rationale behind this was that many worthy candidates reside close enough to attend school but cannot afford the fees associated with a boarding school, nor could the District afford the costs associated with running a full-time boarding school. 
The idea for the school was developed by the Kassena-Nankana DHMT. The Regional Health Management Team (RHMT) was approached for guidance and financial assistance. The two teams together worked to engage the NHRC, which agreed to fund elements of the training that were in keeping with the CHFP protocol. The District Assembly became engaged after stakeholders developed a system through which it could be an active player in recruiting candidates. DANIDA support was enlisted for purchasing computers and motorbikes; JHPIEGO provided training materials.

The school actively recruits candidates from within the Upper East Region, the geographical area where the district is located. Priority is given to candidates from remote areas of the region, individuals most likely to agree to deployment in similar resource-deprived communities post-training. The school works with Navrongo town and close-by communities to find housing for long-distance candidates.

The school strictly adheres to academic standards as established by the Ghana Nurse-Midwives Council. CHPS training modules are integrated into the traditional CHN training curriculum. Background information and skill-learning courses are taught, along with motorbike training, and all students participate in a practicum, being posted to CHOs operating in CHPS zones. Practicum assignment is usually to the candidate's district of residence, thus reducing training costs. Students also receive practical experience at local hospitals and health centers. The program is 18 months in length. At the end, students sit for the same national exams as their counterparts at traditional CHNTS, but in addition they also are graded on a series of CHPS core competencies. The health administrations work to deploy new $\mathrm{CHO}$ to CHPS zones within six months of graduation.

The teaching staff is comprised of six full-time faculty and five part-time adjuncts. One of the full-time staff is a trained nurse with an MPH, another is an environmental health officer, and the rest are professional nurses. The part-time staff includes an MD, social scientists (with the NHRC), computer scientists, and transport officers certified in motorbike training.

The cost of training is approximately $\$ 3,500 / \mathrm{CHO}$, which is only $\$ 100$ greater than the existing CHNTS model. Fees are paid either by individual student's families or through financial aid agreements with District Assemblies and local communities.

Evidence of effective retention already exists. The school reports only 1-2 percent dropout rate. CHO attrition is also reduced by the use of contracts signed by students who seek financial assistance for school costs from District Assemblies and their local communities. These contracts require a minimum one-year term of service upon completion; otherwise the graduating student is required to pay back the amount of the grant.

\section{The Cost of Implementation - James Akazili, Social Scientist, NHRC}

CHPS implementation requires certain standard inputs regardless of local adaptation. Among these are activities for deploying a $\mathrm{CHO}$ and village health workers: community sensitization and entry, construction of the $\mathrm{CHC}$, and training.

Four meetings with chiefs, elders and other opinion leaders in a zone is the average for sensitizing the community for the deployment of CHOs and volunteers. This activity costs $\$ 328$ per zone and includes the cost of drinks and cola nuts at each exchange (\$50) and transport cost per trip (\$32 on average, distance dependent).

Constructing a $\mathrm{CHC}$ requires materials and labor: The main materials used in the CHFP communities are four packets of roofing sheets, $150 \mathrm{bags}$ of cements $(50 \mathrm{~kg}$. each), and wood for roofing (approximately 120 pieces). CHPS implementers need to decide between the use of paid or volunteer labor. Depending 
upon the task and the skill set available within a community, both may be necessary. Acquisition of a plot of land is also required. This is done in consultation with chiefs, elders, and the community. Again, both monetary and in-kind costs may be incurred.

Two models of $\mathrm{CHC}$ were presented with their associated cost. There are several CHC models, but the community should start with what they can do, and scale up as resources become available. However, it is important to note that a more expensive $\mathrm{CHC}$ will last for years and pay for itself in the time saved maintaining a lesser structure.

\section{Former CHC}

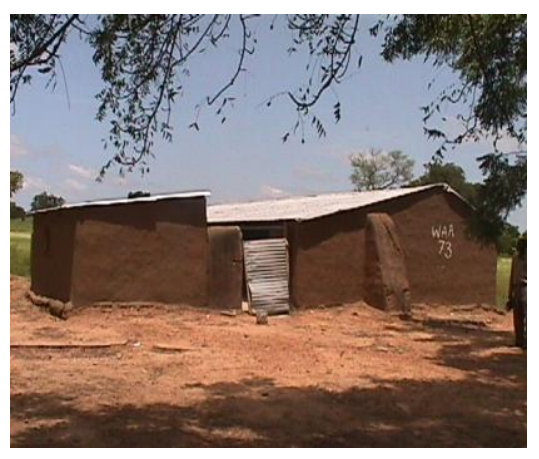

- The cost of this type of $\mathrm{CHC}$ is $\$ 850$ excluding free community labour

- Problem of this facility is the annual renovation cost of up to $\$ 90$

\section{Current $\mathrm{CHC}$}

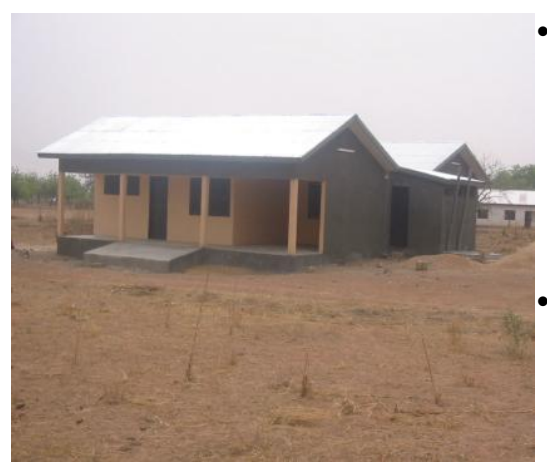

- Cost of constructing this type of $\mathrm{CHC}$ which is more permanent is $\$ 8,500$ excluding community labour

- Excludes cost of:

- solar panel for electricity

- motorola radio

Training involves reorienting a $\mathrm{CHN}$ to become a $\mathrm{CHO}$ by imparting specific additional skills. It also involves the provision of skills to chosen community volunteers. Implementers should expect to pay:

- Allowance for trainees ( $\$ 25$ per $\mathrm{CHO}$ and $\$ 15$ per volunteer)

- Transport allowance ( $\$ 5$ per person, dependent upon distance)

- Allowance for the facilitators (\$10 per facilitator)

- Cost of training materials ( $\$ 35$ per training) 
Durbars are an important avenue for interacting with community members. A minimum of four durbars per zone per year are required as part of the $\mathrm{CHO}$ and volunteer deployment processes. Costs include:

- transport cost $(\$ 32 \times 4$ trips $=\$ 128)$

- presents, including refreshment for the community ( $\$ 65 \times 4=\$ 260)$

The annual costs of maintaining a $\mathrm{CHO}$ in a community must also be considered. Under the auspices of the NHRC, the CHFP experiment team incurred the following costs:

- A rural allowance as incentive for deployment (\$450)

- Monthly supervision ( $\$ 642$, includes transport costs and materials)

- A motorbike $(\$ 3-4,000)$

- Motorbike maintenance and fuel $(\$ 1,800)$

- Domestic equipment and supplies including MIS (beds, mattresses, paper etc) (\$750)

- Pharmaceutical equipment and supplies (\$640)

- Family planning supplies (\$550)

A minimum of three volunteers per zone is recommended. The costs associated with three volunteers' selection, training and deployment:

- Supervision, including transport costs is $\$ 40 /$ month, or $\$ 480 /$ year.

- Bicycle ( $\$ 75 \times 3$ bikes $=\$ 225)$. The lifespan of each bicycle is two years.

- Pharmaceuticals $(\$ 250 /$ year x $3=\$ 750)$

- Family planning supplies ( $\$ 220 /$ year x $3=\$ 660)$

Monthly two-day refresher trainings for CHOs and quarterly trainings for volunteers and their supervisors (i.e., the Volunteer Health Committees) are important for maintaining quality services. Costs for refresher trainings include:

- Transport allowance ( $\$ 325)$

○ One CHO: $\$ 5 \times 11$ months per year $=\$ 55$

○ Three volunteers: $\$ 5 \times 3 \times 3$ times per year $=\$ 45$

○ 15 supervisors: $\$ 5 \times 15 \times 3$ times per year $=\$ 225$

- Allowance for the facilitators $(\$ 990)$

- Cost of training materials $(\$ 250)$

The costs of the Navrongo CHNTS training model are broken down as follows:

- Average capital cost $=\$ 566$

- Average recurrent cost $=\$ 2,987$

- Average total cost $=\$ 3,553$

Overall, the analysis shows that by adding approximately $\$ 2$ per capita to the existing health budget, the program can be implemented. This additional $\$ 2$ has increased benefit in the fact that money spent can reduce fertility by one birth and childhood mortality by at least one-third, along with other benefits.

The costs of deploying a $\mathrm{CHO}$ and the volunteer system do not vary appreciably by district. Other costs do vary from place to place. For example, costs for supervision from subdistrict and district health management teams will depend on distance.

Another cost assessment conducted for the GHS describes the costs of placing one CHO, including community entry and training, dependent upon certain inputs to the $\mathrm{CHC}$ :

New CHC construction \& logistics $(w /$ solar $)=\$ 44,331$

New $\mathrm{CHC}$ construction \& logistics (w/elec/gas/kerosene) $=\$ 26,731$

Renovation \& logistics $(\mathrm{w} /$ solar $)=\$ 32,821$ 
Renovation \& logistics (w/ electricity/gas/kerosene) $=\$ 25,225$

Operational cost including incentives $=\$ 3,373$

It is important to note that there is some cost recovery in terms of services through the government, but they are few. This is the challenge for those implementing the program. As was demonstrated in the Nkwanta replication, donor inputs are still necessary, albeit to a much lesser extent than in the CHFP experiment.

\section{COMMUNITY HEALTH SERVICES IN BURKINA FASO AND SIERRA LEONE}

At the meeting in Navrongo in May 2005, the delegations from the Burkina Faso MOH and the Sierra Leone MOHS had an opportunity to present their respective country's community-based health care strategies.

\section{Burkina Faso}

In 1979, the Government of Burkina Faso adopted the Système de Suivi de la Pauvreté (SSP) (System for Monitoring Poverty) as its health service-delivery strategy. A five-tiered structure was put in place where community facilities served as the entry point to the system and cases were referred upwards from provincial to regional facilities and finally to the national hospital. PSPs (primary service posts) served entire village populations and were comprised of at least two community health "agents" - a health worker and a village midwife. The health worker performed preventive and promotive services, e.g., health education, and provided primary curative services such as first aid, oral rehydration therapy for diarrhea, and treatment of malaria and other such illnesses. The midwife performed home deliveries, provided basic care for newborns and their mothers, held health education talks for mothers, and provided general support for all other health activities.

The strategy was revised in 1985 with the goal of mobilizing communities to resolve their own health problems. In keeping with the philosophies of the Bamako Initiative, community health committees known as COGES were established. COGES participated in health care decision-making and provided support to the community-based health workers and midwives, whose skills were upgraded through a two-month program of training for the health workers and a one-month program for midwives.

In 1995, Burkina took on the challenge of developing an evidenced-based strategy to improve its community-based health services when the Bazega Experiment was launched. Among the approaches tested were the use of community-based delivery (CBD) agents to provide family planning services, and mobilized communities for preventing HIV/AIDS and eradicating female genital cutting (FGC). A 1998 evaluation of Bazega showed the approach had potential.

In 2000, Burkina adopted a national health policy and a 10-year plan of health development. In keeping with the Bazega findings, these emphasize the use of community-based strategies. They also include an essential RH package of services adaptable to local needs. The new processes for implementing community-based services begins with a needs assessment at the village level, followed by community orientation; selection of community-based health care workers; training, equipping, and installing health care workers; implementing a supervisory system, and conducting follow-up and evaluation.

CBD agents, known as SBCs, are key actors at the community level. SBCs must be inhabitants of the community in which they serve. There are several different SBC agents, each with a specific scope of work. The SBC package of services includes FP, HIV/AIDS prevention, combating common diseases, conducting routine deliveries, following vaccinations in the village, and distributing micronutrients. 
In reviewing Burkina Faso's systems of community-based service delivery, the following strengths have been identified:

- The operation of PSPs contributed to the emergence of community participation

- The experience of Bazega provided important lessons learned to stakeholders

- The different types of health officials now in place offer services that complement one another

- The use of community health workers facilitates communication between the health system and population

However, there are also a number of difficulties associated with the SBC strategy:

- Multiplicity of health care officials

- Lack of uniform training content

- A gap between concepts and the social realities of community health

- Weak motivation of community health officials

- Insufficient supervision

- Weak quality of services provided

- Weak support for the community system at other levels of the system

The Burkina MOH, with the direction of its Family Health Division, hopes to design a strategic plan for community health that addresses each of the difficulties described above. It is hoped that the Navrongo experience will be useful in guiding this process.

\section{$\underline{\text { Sierra Leone }}$}

Sierra Leone's health profile reveals a country suffering from numerous problems. It has high rates of infant and maternal mortality coupled with a high burden of diseases such as ARI, pneumonia, diarrhea, and malnutrition. Increasing rates of HIV/AIDS infection are exacerbating the situation. Sierra Leone has a small health budget that is inadequate to meet its needs, and while 60 percent of the services currently being offered are free to vulnerable groups, health facilities are ill-equipped to meet the challenges they face. The effects of the war on the health infrastructure cannot be understated: Twothirds of health facilities are non-functional. Staff attrition is high as a consequence of the conflict. Many health workers either retired or abandoned their posts, and others migrated to safer areas.

Sierra Leone's health system is heavily influenced by donor priorities. UNICEF and the European Union are spearheading efforts to reconstitute it and make it self-sustainable. Working in conjunction with the Ministry of Health and Sanitation (MOHS), a new healthcare structure is being put into place. Under the auspices of a law passed in 2004, the system promotes decentralization with devolution of responsibilities to resuscitated District Councils. Stakeholders are promoting active participation of newly-formed Health Development Committees at the district, chiefdom, and village levels, and they are strengthening District Health Management Teams (DHMT) to supervise efforts.

This newly decentralized system has three main components: The DHMT, the Public Health Unit (PHU) (comprised of a community health clinic (CHC), community health posts (CHP), maternal/child health posts (MCHP)), and the members of the community. The CHC are the equivalent level to Ghana's health centers, and the two health posts are satellite centers that refer to the CHC. CHPs are comprised of three health workers. MCHP provide safe motherhood services and supervise TBAs. Community members play a consultative and promotional role.

The Sierra Leone MOHS is currently in the second year of a four-year MCH intervention trial in three pilot districts. UNICEF is providing funds and technical assistance for this effort. Three intervention 
strategies are being tested: clinic-based services, outreach efforts in the community, and home visits. In addition, three packages of services have been designed, with each one incorporating a different mix of the three service-delivery strategies:

- Immunization Plus. The focus is on increasing immunization rates for common diseases along with Vitamin A supplementation. The PHU staff collaborate with outreach workers. They provide health talks, conduct mobile immunization drives in the community, and conduct household visits to ensure compliance.

- ANC Plus. In addition to providing antenatal care, this strategy incorporates promotion of insecticide-treated nets (ITN), tetanus toxoid injections and the use of iron supplementation. The PHUs collaborate with health outreach workers, TBAs, and community health workers.

- Community Care. This arm focuses on treatment of common diseases, promoting the use of ITN, and conducting health promotion campaigns. PHU staff and community health workers conduct household visits to provide services.

\section{LESSONS LEARNED FROM/RECOMMENDATIONS TO THE GHANA HEALTH SERVICE}

\section{Burkina Faso}

The Burkina Faso MOH plans to replicate GHS policy by placing CHOs first in the zones that are most remote. They also believe that using a $\mathrm{CHO}$ as gatekeeper is a good idea even where health center access is already sufficient, that is, the BF team sees a role for home visits by $\mathrm{CHO}$ as a rational step for improving the use of services and subsequent health outcomes. And, as in Navrongo, they plan on starting small, piloting in 2 districts

The team saw the following strengths with CHPS that could be adapted to local context:

- A sound structure for implementation and administration

- A sound system of identifying needs and priorities of different players prior to developing interventions

- Local recruitment of workers

- Local participation and decision-making powers incorporated into the strategy

- Flexibility in adaptation to local context

Challenges were also seen with replication:

- Implementation is expensive

- Motivation of CHOs and volunteers is time-consuming and difficult

- Cost recovery, in particular, the cost of medications is problematic

- Coverage area of health centers vs. CHO is problematic for Burkina, which has specific guidelines on individual-facility ratios.

The Burkina team recommended that the GHS investigate better means of cost sharing. Also, a standardized health coverage goal, as is used in Burkina, would be deemed useful. In the Burkinabe case, this translates into $60 \%$ coverage of the population residing in $10 \mathrm{~km}$. radius of a facility, and for $5 \mathrm{~km}$ radius, $100 \%$ coverage. In addition, it appears there is no real immersion in the community with existing health centers. Therefore, a more proactive role could be played by subdistrict teams for working directly with the communities. 


\section{$\underline{\text { Sierra Leone }}$}

The health systems in Ghana and Sierra Leone are similar in nature. CHPS experience can be used to expand on the role of the Maternal and Child Health $(\mathrm{MCH})$ Aides, the front-line worker used in community-based service delivery systems in Sierra Leone. MCH Aides can be equated to the CHOs in CHPS

To strengthen the MCH Aides in Sierra Leone to carry out CHPS processes, it will be necessary to engage in the following actions:

- Retraining of MCH Aides to provide the comprehensive services used in CHPS

- Provision of communication systems for referral between health centers and $\mathrm{MCH}$ aides

- A system to provide transportation, maintenance and repairs of motorbikes, communication sets and refrigerators (i.e., cold chain)

- Improve on the referral mechanism in the health posts

- Strengthen supervision and monitoring of the MCH Aides

- Strengthen the health information systems

- Improve on outreach and incorporate a house-to-house approach

- Instruct MCH Aides in community entry skills

The is a need for commitment at different levels of the Sierra Leone health system (e.g., MOHS headquarters, district councils and partners, and communities) as a prerequisite for successful replication. Consensus (advocacy) meetings at the national level with different stakeholders will be necessary to start this initiative.

The team also looked at the CHPS model for guidance with the issue of attrition. This could be addressed through deployment of MCH Aides immediately after training and contracts for new graduates. The planning unit of the MOHS needs to advise the government on this approach.

One major concern of the Sierra Leone team was that CHOs in Ghana have limited authority to conduct deliveries. They believe that changing this policy will go a long way towards improving CHPS impact. Indeed, MCH Aides will be allowed to conduct deliveries.

\section{The Navrongo Consensus and the Way Forward - Dr. Frank Nyonator}

The meeting concluded with the drafting and approval of a consensus statement, launching an international working group to be known as "The ExCHANGE" for "The Expanding Community Health Care Accessibility Network for Governmental Exchanges." The proposed working group agreed to pursue the following goals:

- To develop and share tools for identifying and developing service innovation in community-based health care

- To monitor progress in developing, testing, and scaling up comprehensive community health coverage of all communities by affordable, efficient, and effective services

- To develop effective means of sharing tools, innovation, and experience between countries

All programs are to be designed using evidence-based, problem-solving processes for improving services, specifically in the areas of primary health care and reproductive health/family planning. Members aim to achieve this goal through exchanges that share the experiences of participating countries, expanding the evidence-base for community health development beyond national borders. 
The complete text of the consensus statement appears in an appendix.

Finally, a series of next steps was agreed upon by the participants:

\section{The EXCHANGE}

\section{Next steps:}

- $\quad$ A 4-member steering committee was created. A representative has been appointed from each ExCHANGE country, with technical assistance provided by the Population Council:

$\circ \quad$ Dr. Frank Nyonator, Ghana Health Service, Chair

$\circ \quad$ Dr. P.A.T. Roberts, Sierra Leone Ministry of Health and Sanitation

- Dr. Laurent Ouedraogo, Burkina Faso Ministry of Health

○ Dr. James Phillips, Technical Advisor, Population Council

- Items for immediate follow-up by the ExCHANGE Steering Committee

- Prepare and disseminate formal meeting report to all participants and donors (Assigned to Barry Ravitch, Population Council and Paulina Tindana, NHRC)

- Using consensus statement and formal meeting reports, prepare and disseminate reports to the host country governments, advocating for the ExCHANGE (Drs. Nyonator, Roberts, Ouedraogo)

- Establish an e-mail communication list (Paulina Tindana)

- Set up an internet-based working group, i.e., a website list serve. The WHO International Best Practices (IBP) Consortium can house a website under which the group can engage and promote dialogue. A moderator for the group to be identified. (Liz Warnick, USAID to facilitate; Dr. Nyonator and Paulina Tindana to create).

- Convene a follow-up meeting of the steering committee to review progress and determine next steps. Tentatively scheduled for August (Dr. Nyonator)

- Establish an expanded steering committee comprised of approximately nine members. Members will meet several times a year (exact number TBD).

○ Investigate the possibility of convening a one-year review and assessment meeting (Dr. Phillips)

- $\quad$ Facilitating exchanges

$\circ \quad$ Ghana-Ethiopia-Sierra Leone exchange scheduled 19-27 July at the NHRC

- Other country-to-country exchanges

- It was proposed that a country team from Ghana travel to Burkina Faso and Sierra Leone to present to the governments and share ideas and experiences. To be scheduled soon after the Ethiopia-SL exchange.

- A team from Burkina Faso participated in an exchange with a CHPS demonstration district. Additional Burkina-Ghana field exchanges can be coordinated by GHS to further promote the concept in Burkina or as part of a pilot study.

- The GHS will also work to identify ways to send a Ghana team to hold an exchange in Burkina Faso.

- UNICEF/Sierra Leone will pursue the possibility of sponsoring an ExCHANGE meeting in Sierra Leone. This will be presented during the next funding cycle.

- District-to-district exchanges

- Burkina Faso MOH is developing a micro-pilot study, through which district-to-district exchanges can be facilitated pending results of the experiment

- UNICEF will pursue hosting and sponsoring an exchange for districts in Sierra Leone

- $\quad$ Expanding the ExCHANGE

- The ExCHANGE will create formal mechanisms/criteria for other countries to join.

- Countries interested in joining should demonstrate a commitment to community-based health care and evidence-based practices.

- An application system will be created. 
- Expansion must be linked to resources available for new members to be actively involved in the exchange, as well as appropriate criteria and level of commitment.

- $\quad$ Obtaining funding:

- A cost share arrangement between countries should be explored for future exchange activities.

- USAID will investigate links with its West Africa Regional Program and its cooperating agencies.

$\circ \quad$ The USAID-funded Frontiers in Reproductive Health Program of the Population Council supported the Ghana-Burkina-Sierra Leone exchange. This avenue can be further explored.

- The Council is pursuing opportunities with the Rockefeller Foundation. The Foundations mandate is country-specific, but colleagues at RF are interested.

- The Council will also be pursuing opportunities with donors actively engaged in Ethiopia.

- The European Union and UNICEF can develop in-country support for Sierra Leone

$\circ \quad$ Netherlands funding could be pursued for Burkina Faso.

Participants in the ExCHANGE feel positive about the way forward. They are encouraged by the achievements of the Navrongo model and see benefits to its replication in their respective countries. The partners see this positive outlook as the beginning of the way forward, a chance for sub-Saharan African countries to work together to overcome common challenges of reducing fertility and improving health outcomes for their populations. 


\section{APPENDIX A}
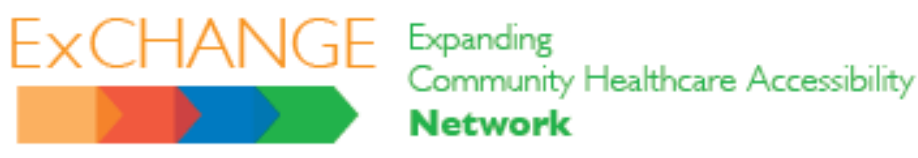

\section{The ExCHANGE Consensus}

(Note: In July, a second exchange was convened between the Ghana Health Service and the Ethiopia Ministry of Health. The consensus statement was revised to incorporate Ethiopia's strategies and goals. The version presented here reflects these changes.)

\section{The Problem}

While international progress in health development has led to a 12 percent decline in childhood mortality in the three final decades of the $20^{\text {th }}$ Century, Africa has been left behind in the health transition:

- In Sub-Saharan Africa, resource constraints hamper access to existing, effective, and affordable health technologies. Funding for primary health care in particular is available at a fraction of the amount deemed essential for even the most minimal configuration of care. Burkina Faso, Ghana, Ethiopia, and Sierra Leone are examples of countries where investment in health care represents a diminishing proportion of national investment in poverty alleviation.

- Political crisis and war have destroyed the health systems in several countries. Sierra Leone is an example of one such country emerging from crisis.

- The need to expand coverage of health services is inhibited by the 'brain drain' of highly skilled health professionals trained with the scarce resources of these countries. Ghana is one example of a country where skilled manpower at all levels is attracted to career opportunities in North America and Europe.

- Even where entire populations are poor, access to reproductive and child health services is most severely limited among the poorest of the poor. Innovations in service delivery methods, health technologies, and communication have yet to benefit these poorest communities.

- Achieving the Millennium Development Goals (MDG) of reducing under-five mortality by twothirds and maternal mortality by three-quarters between 1990 and 2015 will be a daunting task in the face of these constraints. Available evidence suggests that Burkina Faso, Ghana, Ethiopia, and Sierra Leone are failing to achieve child survival MDGs.

\section{The ExCHANGE}

To address these problems, we hereby constitute a regional working group for developing, disseminating, and scaling up innovations in community-based health service delivery. Particular emphasis will be given to applying evidence-based, problem-solving processes for improving services. We aim to achieve this through exchanges that share the experiences of our countries, expanding the evidence base for community health development beyond our borders. This working group will be known as "The ExCHANGE" for "The Expanding Community Health Care Accessibility Network for Governmental 
Exchanges." The ExCHANGE will build international understanding of innovations in participating countries. For example:

- Ghana demonstrates ways in which the sustained application of evidence can guide large-scale programme development and change. The Navrongo experiment demonstrates ways to consult with communities, plan services, and build alliances between community leaders and health providers. Local institutions can be used in many African settings to organize and deliver health services, and tools developed in Ghana illustrate practical mechanisms for monitoring progress in attaining health MDG. A national programme, known as the Community-based Health Planning and Services (CHPS) Initiative, demonstrates means of reducing the financial, access, and social barriers to health service utilisation. CHPS is a national strategy for decentralization that enables communities to develop and sustain affordable, efficient, accountable, equitable, and high quality services. Ghana provides examples of practical strategies for developing capacity and leadership at the district level. Districts demonstrating progress with developing community health services are engaged in the task of leading other districts in the process. Exchanges between communities, frontline workers, managers, and policy makers build clarity and competence about practical steps in developing services. CHPS develops leadership from action.

- Sierra Leone provides a model for developing health services in a post-crisis setting. The country is estimated to have the highest mortality rate of any in Africa. With the support of humanitarian assistance agencies , district-level, community-based health service systems have been developed that constitute local leadership and deploy community health workers known as Maternal and Child Health Aides (MCH Aides). These MCH Aides provide a broad range of curative, preventative and midwifery services. Sierra Leone experience demonstrates that a large complement of integrated management of childhood illness, safe motherhood, and primary health care services are feasible and affordable under conditions of great institutional stress. Partnership with Ghana will provide Sierra Leone with an orientation on how to utilise research methodology to develop its programme.

- In Ethiopia, the Ministry of Health launched the "Health Extension Package" (HEP) in 2001 as an integral component of its Health Sector Development Programme. HEP is a community-based programme strategy designed to meet the basic health needs of remote populations and to strengthen community participation and decision-making. Like Ghana's CHPS initiative, HEP calls for the deployment of health extension workers to the health posts of each kebele (grassroots government administration). However, as yet, there is limited testing of programme options for identifying practical solutions to operational challenges. Partnership with research institutions will be instrumental in guiding national expansion of the HEP initiative in the future. Exchanges with the Navrongo team will explore prospects for designing research that will answer strategic questions about ways to develop HEP efficiency, quality, and efficacy.

- In Burkina Faso, constraints to health care access closely parallel problems that confronted Ghana in the pre-CHPS era. Although the Burkina Faso population's access to health care is fairly good (the average distance to a health centre is $8.6 \mathrm{~km}$.), only $33 \%$ of the population attend health centres. The introduction of qualified health agents at the community level has been associated with improved health care coverage at the health centre level; enhanced quality of health care services; and reduced fertility, morbidity, and mortality rates among mothers and children. Exchanges with Ghana are providing Burkina Faso with practical examples on how research can be incorporated into their programme development agenda. 


\section{The Way Forward}

Objectives. Taken together, community health service development initiatives in ExCHANGE countries provide a basis for learning and action that could solve the health development problems and contribute to the policy needs of our neighbours. Combining our respective ideas and leadership will accelerate the pace of innovation, trial, and scaling up. Learning across borders will contribute to the process of developing general principles of evidence-based health system reform.

We resolve:

- to develop and share tools for identifying and developing service innovation in community-based health care;

- to monitor progress on developing, testing, and scaling up comprehensive community health coverage for all communities by affordable, efficient, and effective services; and

- to develop effective means of sharing tools, innovations, and experiences between our countries. Lessons from the evidence-based CHPS approach are relevant to the health development needs of Burkina Faso, Sierra Leone, and Ethiopia.

Participating governments resolve to constitute the ExCHANGE:

- to identify, diagnose, and solve problems that prevent the implementation of community health care service delivery;

- to develop community-based health service innovation, evidence that innovations work, and evidence to guide the utilisation of innovation for scaling up community-based health care;

- to develop a programme of district-to-district exchanges where teams of frontline health providers, nurse supervisors, programme coordinators and districts managers in Ghana will be paired with counterparts from districts in Sierra Leone and Burkina Faso;

- to convene an international working group of senior policy officials, regional authorities, and innovating district leaders to guide the process of interactions, foster the utilisation of innovation, and disseminate lessons to the health policy community; and

- to constitute a communication capability that documents our innovations and disseminates experiences among African health managers and policy makers.

ExCHANGE will build problem-solving, evidence-based programme development capacity in our countries that will extend beyond our borders. We will demonstrate practical means of responding to the health development needs of our most impoverished citizens. We will demonstrate practical methods for health sector reform in countries coping with extreme adversity or emerging from political crisis.

Governance. The Ghana Health Service will constitute a Secretariat for coordinating the ExCHANGE and will designate an ExCHANGE Coordinator. Participating countries will designate a representative for coordinating communication, action, and learning within each country and liaising with the ExCHANGE. 
Mechanisms. Initially, The ExCHANGE will focus on the transfer of innovation from Ghana to participating countries. Subsequently, it will foster the dissemination of innovation in community health service development among member countries. This will involve:

- Peer learning. Partnering district, regional, and national policy units to transfer experience with innovation, action, and capacity between countries. ExCHANGE will build upon peer leadership models developed in Ghana. In turn, this will help participating countries develop pilot or experimental studies in community health and family planning.

- Learning through trial. Pilot and experimental systems developed in each country will be used to inform scaling up and action within the other participating countries.

- Evidence. The Navrongo Health Research Centre and the Population Council will provide technical support for monitoring the exchange process and evaluating progress within participating countries.

- Policy leadership. Subject to the availability of funding, senior policy exchanges will be convened on rotation among the participating countries.

- Communication. The ExCHANGE secretariat will develop web communication mechanisms for the ExCHANGE network so that lessons learned are shared with neighbouring countries and the health development community. 


\section{APPENDIX B}

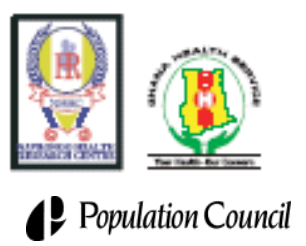

\section{NHRC/GHS/POPULATION COUNCIL CHPS WITHOUT BORDERS INTERNATIONAL EXCHANGE PROGRAMME OF EVENTS}

\section{DAY 1 (May 12) POLICY/PROGRAMME ORIENTATION}

\section{Morning}

\subsection{0 - 10.00 a.m. Opening Ceremony}

Welcome Address/ Overview of the Navrongo Health Research Centre

Dr. Abraham Hodgson, Director, Navrongo Health Research Centre (NHRC)

Introductory remarks

Dr. Frank Nyonator, Director, Policy Planning, Monitoring, and Evaluation Division, GHS

Prof. Fred Binka, Former Director, NHRC; Executive Director, INDEPTH Network

Dr. James Phillips, Senior Associate, Population Council, New York.

Mr. George Dan-Yare, District Chief Executive, Kassena Nankana District (KND)

10.00 - 10.30 a.m. Snack Break

10.30 a.m. - 12.30 p.m. The Navrongo Community Health and Family Planning (CHFP) Experiment / Chair: Prof. Fred Binka

Background and Design (Dr. John Williams, Principal Investigator, CHFP)

Social Context (Dr. Patricia Akweongo, NHRC)

Implementation Part I (Ms. Rofina Asuru, District Director of Health Services, KND)

12.30 - 2.00 p.m. Lunch Break

\section{Afternoon}

$2.00-4.30$ p.m.

The Navrongo Experiment Continued / Chair: Prof. Fred Binka

Implementation Part II (Mr. Robert Alirigia, Field Coordinator, CHFP)

The Impact of the Experiment (Dr. Ayaga A. Bawah, Head, Navrongo Demographic Surveillance System)

Questions and Discussion

6.30 p.m. Welcome Reception with Cultural Performance (NHRC Tennis Court) 
DAY 2 (May 13) REPLICATION AND DISCUSSIONS

Morning

8.30 a.m. - 10.00 p.m. Replicating Navrongo /Chair: Dr. Patricia Akweongo

The Nkwanta Story (Dr. J. Koku Awoonor-Williams, District Director of Health Services, Nkwanta District / Director, Nkwanta Health Development Centre / National CHPS Coordinator)

The Abura Asebu Kwamenkesi (AAK) Story (Ms. Pat Antwi, District Director of Health Services, AAK District)

10.00 - 10.30 a.m. Snack Break

10.30 a.m. - 12:30 p.m. Replicating Navrongo (Continued)

Panel: Community Health Officers / Chair: Ms. Rofina Asuru

Problems Associated with Community Health Service Delivery

Panel: Community Health Services in Burkina Faso and Sierra Leone /

Chair: Dr. Cornelius Debpuur, NHRC

Discussion of Programmes in Burkina Faso and Sierra Leone

12.30 - 1.30 p.m. Lunch Break

Afternoon

1.30 - 4.30 p.m. Field Demonstration

Visit to a Community Health Compound

- Supervisory roles

- Practical aspects of Community Health Officer (CHO) activities

- Construction of Community Health Compounds (CHCs) and community support

Demonstration of the Zurugelu Dimension

- Community durbar - Introduction of volunteers, demonstration of community participation through health committees

- Reception with traditional leaders and district officials

DAY 3 (May 14) MANAGING COMMUNITY HEALTH SERVICES

8.00 a.m. - 3.30 p.m. Visit to Bawku West District / Chairs: Ms. Rosemond Azure, District Director of Health Services, Bawku West District; and Ms. Evelyn Adda, Principal Investigator, Bawku West CHPS Innovator Initiative

Practical demonstration of:

- Supervision

- Community entry/community mobilization

- Volunteer recruitment, training, reporting, monitoring and evaluation 
- Community health service operations

- Sustaining community support

- Performance monitoring

- Logistics

- Service quality and intensity

3.30 - 4.30 p.m. End-of-day round table discussion / Chair: Dr. Joseph Amankwa, Regional Director of Medical Services, Upper East Region)

$6.00-6.45$ p.m. Video Documentary on the CHFP and FGM projects

(NHRC Parliament)

DAY 4 (May 15) THE COMMUNITY-BASED HEALTH PLANNING AND

SERVICES (CHPS) INITIATIVE

Morning

8.30 - 10.00 a.m. The Scaling-up Process / Chair: Dr. J. Koku Awoonor-Williams

Training and Manpower Development (Ms. Rofina Asuru)

CHPS Coverage and Problems (Dr. Frank Nyonator)

10.00 - 10.30 a.m. Snack Break

10.30 a.m. -12.30 p.m. The Navrongo Female Genital Mutilation Initiative /

Chair: Dr. Patricia Akweongo, Principal Investigator

12.30 - 2.00 p.m. Lunch Break

Afternoon

$2.00-5.00$ p.m. Visit to Tourist Sites (Paga crocodile pond and border, slave market, Tono dam)

DAY 5 (May 16) TRAINING, QUALITY ASSURANCE \& SCALING UP

Morning

9.00 a.m. -12.30 p.m. Visit to the Navrongo Community Health Nurse Training School / Chair: Mr. David Amalba, School Principal

Curriculum

Problems addressed by the Navrongo pre-service training approach

Exchange with students

In-service training needs and activities/assessing quality

Nurse recruitment

12.30 - 2.00 p.m. Lunch Break 


\section{Afternoon}

2.00 - 4.00 p.m. Planning a Programme / Chair: Dr. James Phillips

Scaling-up success:

- The cost of implementation (Mr. James Akazili, NHRC )

- Strategies for external, district, and community resource development (Dr. Koku Awoonor-Williams)

Questions and Discussion

\section{DAY 6 (May 17) NEXT STEPS / Chair: Dr. John Williams}

\subsection{0 a.m. - 4.30 p.m. Open Forum on a Draft Joint Statement of Collaboration}

The Relevance of the Navrongo Approach to Developing Health Services in Post-Conflict Sierra Leone (Representative from the Ministry of Health and Sanitation, Freetown)

The Relevance of the Navrongo Approach to the Burkina Community Health Project (Representative from the Department of Family Health, Ministry of Health, Ouagadougou)

Discussion/Drafting of a Joint Statement of Goals and Mechanisms for Future Collaboration

Closing Remarks - Dr. James Phillips

6.00 p.m. $\quad$ Farewell Cocktail (Tennis Court, NHRC) 


\section{APPENDIX C}

\section{GHANA-BURKINA FASO-SIERRA LEONE EXCHANGE LAUNCH CONFERENCE 11-18 MAY 2005 NAVRONGO HEALTH RESEARCH CENTRE, NAVRONGO, GHANA OFFICIAL PARTICIPANTS LIST}

Ms. Evelyn Adda

CHPS Coordinator

Bawku West District Health Administration

c/o Regional Health Directorate

Ghana Health Service

Private Mail Bag

Bolgatanga, UER

Ghana

Phone: +233-24-443-8056

e-mail: seekitan@yahoo.com

Mr. James Akazili

Research Officer

Navrongo Health Research Centre

P.O. Box 114

Navrongo, UER

Ghana

Phone: +233-483-4435

e-mail: jakazili@navrongo.mimcom.net

Dr. Patricia Akweongo

Social Scientist

Navrongo Health Research Centre

P.O. Box 114

Navrongo, UER

Ghana

Phone: +233-24-313-8376

e-mail: pakweongo@navrongo.mimcom.net

Mr. Robert Alirigia

Field Coordinator

Navrongo Health Research Centre

P.O. Box 114

Navrongo, UER

Ghana

Phone: +233-742-22310 +233-24-437-4081

e-mail: ralirigia@navrongo.mimcom.net
Dr. David Amalba

Principal

Navrongo Community Health Nurse

Training School

c/o Kassena-Nankana District Health

Administration

P.O. Box 8

Navrongo, UER

Ghana

Phone: +233-742-22515 or +233-24-474-8487

e-mail: damalba@yahoo.com

Ms. Patricia Antwi

Director of Health Services

AAK District

c/o Regional Health Administration

Ghana Health Service

P.O. Box 63

Cape Coast, Ghana

Phone: +233-24-428-9249

e-mail: pantwi@hotmail.com

Ms. Rofina Asuru

Director of Health Services

Kassena-Nankana District Health

Administration

P.O. Box 8

Navrongo, UER

Ghana

Phone: +233-742-22313 +233-24-470-4697

e-mail: rasuru@navrongo.mimcom.net

Ms. Veronica Awogbo

Meeting Facilitator

Navrongo Health Research Centre

P.O. Box 114

Navrongo, UER

Ghana

Phone: +233-742-22310

e-mail: vawogbo@navrongo.mimcom.net 
Dr. John Koku Awoonor-Williams

Director of Medical Services

Nkwanta District

Ghana Health Service

P.O. Box 54

Nkwanta, VR

Ghana

Phone: +233-24-456-4120

e-mail: kawoonor@africaonline.com.gh

Ms. Rosemond Azure

Director of Medical Services

Bawku West District

c/o Regional Health Directorate

Ghana Health Service

Private Mail Bag

Bolgatanga, UER

Ghana

Phone: +233-24-452-0810

e-mail: asintarige@yahoo.com

Dr. Ayaga Bawah

Berelson Postdoctoral Fellow

Population Council

One Dag Hammarskjold Plaza

New York, NY 10017

USA

Phone: +1-212-339-0692

e-mail: abawah@popcouncil.org

Professor Fred Binka

Executive Director

INDEPTH Network

P. O. Box KD 213

9 Adenkum Loop

Kanda, Accra

Ghana

Phone: +233-21-254-752 +233-20-813-1031

e-mail: fred.binka@indepth-network.org

Ms. Charity Bukari

Meeting

Navrongo Health Research Centre

P.O. Box 114

Navrongo, UER

Ghana

Phone: +233-24-363-0444

e-mail: cbukari@navrongo.mimcom.net
Dr. Patrice Combary

Regional Health Director

Burkina Faso Ministry of Health

Ouagadougou, Burkina Faso

Phone: +226-50-440-106

e-mail: patricecombary@ hotmail.com

Dr. Norbert Coulibaly

Regional Health Director

Centre-est Tenkodogo Région

Burkina Faso Ministry of Health

Phone: +226-40-710-127

e-mail: drs.tenkodogo@ sante.gov.bf

Dr. Cornelius Debpuur

Social Scientist

Navrongo Health Research Centre

P.O. Box 114

Navrongo, UER

Ghana

Phone: +233-742-22310

e-mail: cdebpuur@navrongo.mimcom.net

Dr. Sarah Harbison

USAID Office of Population/3.06-154

1300 Pennsylvania Avenue N.W.

Washington, D.C. 20523-3100

Phone: +1-202-712-4536

e-mail: sharbison@usaid.gov

Dr. Sié Roger Hien

Burkina Faso Ministry of Health

Ouagadougou, Burkina Faso

Phone: +226-50-324-662

e-mail:hien_sie@hotmail.com

Dr. Abraham Hodgson

Director

Navrongo Health Research Centre

P.O. Box 114

Navrongo, UER

Ghana

Phone: +233-742-22380

e-mail: ahodgson@navrongo.mimcom.net 


\author{
Dr. Clifford Kamara \\ Director of Planning and Information \\ Sierra Leone Ministry of Health and Sanitation \\ Room E507, Fifth Floor, East Wing, \\ Youyi Building, Brookfields, \\ Freetown, Sierra Leone \\ Phone: +232-22-240-068 \\ $+232-76-601-494$ \\ e-mail: cwkamara@hotmail.com \\ Mr. Adams Kasanga \\ Research Specialist \\ Population Council \\ Medlab Building \\ Roma Road \\ Roman Ridge, Accra \\ Ghana \\ Phone +233-21-780-711 \\ e-mail: akasanga@pcaccra.org \\ Dr. Kedrick Kiawoin \\ Project Officer \\ Health and Nutrition Division \\ UNICEF/Sierra Leone \\ P.O. Box 221 \\ Freetown, Sierra Leone \\ Phone: +232-22-234-996 \\ e-mail: kkiawoing@unicef.org \\ Dr. Alex Nazzar \\ Monitoring and Evaluation Advisor \\ AWARE-RH \\ Demmco House \\ 1 Crescent, Dzorwulu \\ Airport West, PMB CT 242 \\ Accra, Ghana \\ Phone: +233-21-786-152 \\ e-mail: anazzar@aware-rh.org \\ Dr. Frank Nyonator \\ Director \\ Policy Planning, Monitoring and Evaluation \\ Division \\ Ghana Health Service \\ Private Mail Bag \\ Accra, Ghana \\ Phone: +233-21-684-272 \\ e-mail: nyonator@africaonline.com.gh
}

Dr. Philomena Nyarko

Program Officer

FRONTIERS in Reproductive Health

Population Council

Medlab Building

Roma Road

Roman Ridge, Accra

Ghana

Phone: +233-21-780-711

e-mail: pnyarko@pcaccra.org

Dr. Laurent Ouedraogo

Burkina Faso Ministry of Health

Ougadougou, Burkina Faso

Phone: +226-50-307-778

e-mail: laurentio@voila.fr

Dr. James Phillips

Senior Associate

Population Council

One Dag Hammarskjold Plaza

New York, NY 10017

USA

Phone: +1-212-339-0670]

e-mail: jphillips@popcouncil.org

Dr. Samuel Pratt

Project Officer

Health and Nutrition Division

UNICEF/Sierra Leone

P.O. Box 221

Freetown, Sierra Leone

Phone: +232-22-234-996

e-mail: spratt@unicef.org

Mr. Barry Ravitch

Program Manager

Policy Research Division

Population Council

One Dag Hammarskjold Plaza

New York, NY 10017

USA

Phone: +1-212-339-0632

e-mail: bravitch@popcouncil.org

Dr. Prince A. T. Roberts

Deputy Director for Primary Health Care

Sierra Leone Ministry of Health and Sanitation

Freetown, Sierra Leone

Phone: +232-76-666-960

e-mail: taiworob@yahoo.com 
Ms.. Evelyn Sakeah

Research Officer

Navrongo Health Research Centre

P.O. Box 114

Navrongo, UER

Ghana

Phone: +233-24-424-5237

e-mail: esakeah@navrongo.mimcom.net

Ms. Laure Salembere

Netherlands Ministry of Foreign Affairs

Boîte Postale 1302

Ouagadougou

Burkina Faso

Phone: +226-50-306-134

e-mail: Laure.Salembere@minbuza.nl

Ms. Lydia Saloucou

Research Coordinator and Country Director

Population Council

01 BP 6250

Ouagadougou 01,

Burkina Faso

Phone: +226-50-311-242

e-mail: 1saloucou@popcouncil.bf

Dr. Jibao Sandy

Koinadugu District Medical Officer

Sierra Leone Ministry of Health and Sanitation

Freetown, Sierra Leone

Phone: +232-76-603-269

e-mail: nazeria2005@yahoo.com

Dr. Momodu Sesay

Kono District Medical Officer

Sierra Leone Ministry of Health and Sanitation

Freetown, Sierra Leone

Phone: +232-76-666-960

e-mail: mmdssy@yahoo.com

Dr. Samuel Juana Smith

Bombali District Medical Officer

Northern Province

Sierra Leone Ministry of Health and Sanitation

Freetown, Sierra Leone

Phone: +232-76-611-042

e-mail: samueljuana@yahoo.com
Dr. Mesfin Teferi

International PHC Adviser

Health Sector Support Programme

European Union/Sierra Leone

P.O. Box 1399

Freetown, Sierra Leone

Phone: +232-76-738-004

e-mail: hailem707@yahoo.com

Mr. Titus Tei

Administrator

INDEPTH Network

P. O. Box KD 213

9 Adenkum Loop

Kanda, Accra

Ghana

Phone: +233-21-254-752

e-mail: titus.tei@indepth-network.org

Ms. Paulina Tindana

Communications Specialist

Navrongo Health Research Centre

P.O. Box 114

Navrongo, UER

Ghana

Phone: +233-24-363-0444

e-mail: ptindana@navrongo.mimcom.net

Ms. Elizabeth Warnick

Senior Advisor for Utilization

USAID

GH/PRH/RTU 3.6-160

1300 Pennsylvania Avenue NW

Washington, DC 20523-3601

Phone: +1-202-712-5586

e-mail: ewarnick@usaid.gov

Dr. John Williams

Principal Investigator, CHFP

Navrongo Health Research Centre

P.O. Box 114

Navrongo, UER

Ghana

Phone: +233-742-22380

e-mail: jwilliams@navrongo.mimcom.net 